\title{
The Stay-Green Mutation Contributes to Enhanced Antioxidative Competence and Delays Leaf Senescence in Soybean Hybrid Z1
}

\author{
Peng Wang ${ }^{1}$, Siyu Hou ${ }^{1}$, Hongwei Wen ${ }^{1}$, Quanzhen Wang ${ }^{2}$ and Guiquan $\mathrm{Li}^{{ }^{*}}$ \\ ${ }^{1}$ College of Agriculture, Shanxi Agricultural University, Taigu 030801, China \\ ${ }^{2}$ College of Grassland Agriculture, Northwest A\&F University, Yangling 712100, China \\ *For correspondence: li-gui-quan@126.com; 61901623@qq.com \\ Received 23 June 2020; Accepted 22 October 2020; Published 10 January 2021
}

\begin{abstract}
The new soybean stay-green variety Jinda Zhilv No. 1 (Z1) was obtained through crossing a stay-green mutant with the superhigh yielding soybean cultivar Jinda No. 74 (JD74). Here, we compared the antioxidant enzyme activities and reactive oxygen species content of the Z1 and JD74 varieties under natural and dark-induced senescence. Dark treatment was imposed at the seedling stage for 13 days. Fluorescence quantitative PCR was used to investigate the expression of isozyme genes related to superoxide dismutase (SOD), catalase (CAT) and ascorbate-glutathione cycle. The results indicated that compared with JD74, Z1 exhibited enhanced antioxidant enzyme activity, with rates of hydrogen peroxide and superoxide anion accumulation being lower in Z1 after flowering. The expression levels of antioxidant enzyme isogenes, including $M n-S O D, C h l C u / Z n-S O D$, peroxisome $\mathrm{Cu} / \mathrm{Zn}$-SOD, CAT5, MDHAR1, and DHAR3, were higher in Z1 than in JD74 during the seed-filling stage. After 6 days of dark treatment, the membrane system of JD74 leaves showed severe oxidative damage and the leaves had turned completely yellow. These changes were accompanied by reduced contents of chlorophyll and soluble protein after 13 days of dark treatment. In contrast, Z1 was observed to be more tolerant to dark stress. Its internal reactive oxygen metabolism balance remained unimpaired, and the leaves showed no obvious senescence traits. In conclusion, the higher antioxidant capacity in Z1 contributes to delayed leaf senescence, which is a significant finding with respect to the application of stay-green mutants in soybean breeding and germplasm innovation. (C) 2021 Friends Science Publishers
\end{abstract}

Keywords: Antioxidant potential; Ascorbate-glutathione cycle; Breeding; Stay-green mutation

\section{Introduction}

Leaf senescence in higher plants is closely related to the accumulation of reactive oxygen species (ROS) and the associated oxidative stress (Shokri-Gharelo and Noparvar 2018). The major ROS in plants include superoxide anion $\left(\mathrm{O}_{2}{ }^{-}\right)$, hydrogen peroxide $\left(\mathrm{H}_{2} \mathrm{O}_{2}\right)$ and the hydroxyl radical $(\mathrm{OH})$, which are important signalling molecules that play roles in signal transduction pathways during plant development and the response to stress (Choudhury et al. 2017). However, when produced in excess, ROS can become toxic and promote oxidative damage to cell membranes and biomacromolecules (Hussain et al. 2018), which in turn leads to cellular ageing and death.

Plants are, however, equipped with an internal antioxidant enzyme protection system (i.e., antioxidant enzymes and antioxidant substances) that is responsible for ROS scavenging and protects cell membranes from peroxidation damage (Aziz et al. 2014). Activity of the enzyme superoxide dismutase (SOD) serves as the first line of defence against oxygen free radicals (Raja et al. 2020) via catalysing the conversion of $\mathrm{O}_{2}^{--}$to $\mathrm{H}_{2} \mathrm{O}_{2}$ and molecular oxygen (Wang et al. 2018). Catalase (CAT) and ascorbate peroxidase (APX) are the main enzymes that scavenge $\mathrm{H}_{2} \mathrm{O}_{2}$ (Farooq et al. 2019), the former of which has high activity and does not require the presence of antioxidant substrates to scavenge $\mathrm{H}_{2} \mathrm{O}_{2}$ (Mhamdi et al. 2010). APX has a higher affinity for $\mathrm{H}_{2} \mathrm{O}_{2}$ but lower activity than CAT (Huang et al. 2017) and its ability to eliminate $\mathrm{H}_{2} \mathrm{O}_{2}$ is dependent on the presence of ascorbate (ASA) and glutathione (GSH). In the ASA-GSH cycle, APX functions together with other key enzymes, including monodehydroascorbate reductase (MDHAR), dehydroascorbic acid reductase (DHAR) and glutathione reductase (GR), to regulate the metabolic balance of $\mathrm{H}_{2} \mathrm{O}_{2}$ during different developmental phases and in different subcellular structures (Raja et al. 2017). Another antioxidant enzyme, peroxidase (POD), performs dual roles, acting as both a scavenger of $\mathrm{H}_{2} \mathrm{O}_{2}$ and participating in the generation of ROS during plant senescence, and can accelerate the peroxidation of cell membrane lipids.

These antioxidant enzymes occur in the form of multiple isoenzymes encoded by small gene families. There are, for example, three SOD isozymes in plants, namely, Mn-SOD, Fe-SOD and Cu/Zn-SOD, which combine with 
different metal cofactors and are located in different subcellular structures (Blackney et al. 2014; Zhou et al. 2017). In Arabidopsis, three isozymes encoded by CAT1, CAT2 and CAT3 play different roles in $\mathrm{H}_{2} \mathrm{O}_{2}$ removal via different pathways (Wang et al. 2019). These antioxidant isozymes perform unique functions in response to different abiotic stressors (Morita et al. 2011). For example, enhanced Mn-SOD activity is the main factor contributing to the delayed senescence of maize leaves (Prochazkova et al. 2001). $\mathrm{Cu} / \mathrm{Zn}-\mathrm{SOD}$, which is detected in numerous cell compartments, is the most abundant form of SOD in plant cells (Leonowicz et al. 2018) and transgenic rice plants overexpressing $\mathrm{Cu} / \mathrm{Zn}$-SOD show strong drought resistance (Gill and Tuteja 2010). Arabidopsis chloroplast APX protects the photosynthetic elements from oxidative damage (Shigeoka et al. 2002), whereas cytoplasmic MDHAR and chloroplast/mitochondrial MDHAR are induced in response to abiotic stresses such as salinity, light, or cold (Yoon et al. 2004). Drought stress inhibits chloroplast MDHAR and peroxisome MDHAR expression in wheat but increases the levels of cytoplasmic MDHAR transcription (Secenji et al. 2010).

The stay-green mutations in different plants generally result in the retention of leaf colour during senescence and even after death (Kusaba et al. 2013). Stay-green mutants are of five types and can be further divided into functional and non-functional stay-green mutants (Thomas and Howarth 2000). Some functional stay-green mutants exhibit enhanced antioxidant capacities (Prochazkova et al. 2001), delayed senescence, and prolonged photosynthetic activities (Wang et al. 2020). Tian et al. (2015) reported that the wheat stay-green mutant tasgl has a stronger antioxidant capacity than wild-type (WT) plants at the grain-filling stage and under conditions of drought stress. To date, however, there have been few studies that have examined the antioxidant physiology of stay-green soybean, particularly the dynamic expression of antioxidant enzyme isogenes during leaf senescence.

We previously identified a natural soybean stay-green mutant in the field, the leaves of which remained green and showed no signs of yellowing during leaf senescence, even after being shed (results unpublished). However, the agronomic characters and yield performance of this staygreen mutant were found to be poor. To take advantage of the beneficial properties of the stay-green mutation, we hybridised this mutant with the common soybean cultivar Jinda No. 74 (JD74) and generated a new stay-green variety, Jinda Zhilv No. 1 (Z1), which was derived from a staygreen hybrid line after 7 years of self-crossing. JD74 has strong drought resistance and exhibits beneficial agronomic traits and high yield, and indeed, this variety once set the record for super high yield of summer soybean in the Huang-Huai-Hai area of China. The new stay-green variety Z1 has obvious hybridization advantages, combining the beneficial traits of the stay-green phenotype with the excellent characters of JD74.

In the present study, with a view towards providing important information regarding the effects of the stay-green mutation on antioxidative competence in hybrid soybean, we sought to focus on the expression profiles of antioxidant enzyme-related genes during leaf senescence. In addition, we aimed to elucidate the characteristics of ROS metabolism during leaf senescence induced by dark treatment (DT). We believe that the findings of this study will make a significant contribution to the application of stay-green mutants in soybean breeding and germplasm innovation.

\section{Materials and Methods}

\section{Plant materials}

The new soybean stay-green variety Jinda Zhilv No. 1 (Z1) is characterised by leaves that do not turn yellow during senescence and a green seed coat. One of the parents, JD74, was used in the present study for comparative purposes.

\section{Field experiments}

In 2017 and 2018, plants of both varieties were grown in an experimental field at Shanxi Agricultural University, Taigu, China. Trials were conducted based on a random block design, in which there were three replicate plots for each variety, with each plot comprising six rows. In each $6 \mathrm{~m}$ row, plants were spaced at $0.5 \mathrm{~m}$. At anthesis, similarly sized plants that flowered on the same day were selected for listing and marking. Fully expanded functional leaves of the marked plants were collected at 7-day interval, rapidly frozen in liquid nitrogen, and stored at $-80^{\circ} \mathrm{C}$ until used for further analysis.

\section{Dark treatment (DT) in the laboratory}

Following sterilisation with $0.2 \%$ sodium hypochlorite, soybean seeds were germinated on filter paper moistened with water for $72 \mathrm{~h}$ at $25^{\circ} \mathrm{C}$. The seeds were then placed in whole trays containing soil supplemented with growth medium. For the dark-induced senescence treatment, whole plants, after the second compound leaf had unfolded, were transferred to complete darkness at $25^{\circ} \mathrm{C}$ and watered normally. Samples were harvested at 0,6 , and 13 days after the initiation of DT, and the relevant physiological indices were determined.

\section{Biochemical analysis}

For the extraction of chlorophyll, approximately $0.1 \mathrm{~g}$ of fresh leaves was immersed in $20 \mathrm{~mL}$ of ice-cold $80 \%$ (v/v) acetone for $48 \mathrm{~h}$ in darkness. Extract absorbance was measured using a spectrophotometer (UV-1200; MAPADA, China) at 663, 645, and $470 \mathrm{~nm}$, and the chlorophyll content was calculated according to the formula reported by Porra et al. (1989).

$\mathrm{H}_{2} \mathrm{O}_{2}$ content was determined using a 
spectrophotometer (Zou 2000). Leaf samples (1 g) were ground with $10 \mathrm{~mL}$ of cold acetone in an ice bath, and the resulting homogenate was centrifuged at $15000 \times g$ for 20 min. A mixture containing $1 \mathrm{~mL}$ supernatant, $0.1 \mathrm{~mL}$ titanium sulphate $(5 \% \mathrm{~W} / \mathrm{V})$ and $0.2 \mathrm{~mL}$ ammonia water was centrifuged at $3000 \times g$ for 10 min after forming a precipitate. After discarding the supernatant, the precipitate was washed three to five times with acetone and dissolved in $5 \mathrm{~mL}$ concentrated sulfuric acid. The absorbance of the resulting preparation was determined at $415 \mathrm{~nm}$.

Soybean leaves $(0.1 \mathrm{~g})$ were ground with $4 \mathrm{~mL}$ of precooled $50 \mathrm{mmol} / \mathrm{L}$ phosphate buffer $(\mathrm{pH} 7.8$, containing 0.1 $\mathrm{mmol} / \mathrm{L}$ EDTA and $1 \% \mathrm{PVP}$ ) in an ice bath, and the mixture was centrifuged at $12000 \times g$ for $20 \mathrm{~min}$ at $4^{\circ} \mathrm{C}$. The supernatant was used to determine enzyme activities and superoxide anion, malondialdehyde (MDA), and soluble protein contents (described below).

SOD activity was measured as described previously by Dhindsa et al. (1981) with slight modification. The reaction mixture contained $2.7 \mathrm{~mL}$ of methionine $(14.5$ $\mathrm{m} M), 0.1 \mathrm{~mL}$ of nitroblue tetrazolium chloride (NBT) $(2.25$ $\mathrm{m} M), 0.1 \mathrm{~mL}$ of EDTA-Na $\mathrm{N}_{2}(3 \mathrm{~m} M)$, and $0.1 \mathrm{~mL}$ of riboflavin $(60 \mu \mathrm{M})$, all solutions of which were prepared with $50 \mathrm{~m} M$ phosphate buffer. The reaction was initiated by adding $40 \mu \mathrm{L}$ of enzyme extract and placing the tubes under $4000 \mathrm{~lx}$ lamps for $20 \mathrm{~min}$. A complete reaction mixture lacking enzyme extract served as a control. The formation of blue formazan, induced by the photoreduction of NBT, was recorded spectrophotometrically at $560 \mathrm{~nm}$, with a nonirradiated complete reaction mixture lacking enzyme extract being used as a blank.

CAT activity was measured according to method described by Teranishi et al. (1974) with slight modification. The reaction mixture contained $100 \mathrm{~mL}$ of phosphate buffer $(0.15 \mathrm{M}, \mathrm{pH} 7.0)$ and $154.6 \mu \mathrm{L}$ of $\mathrm{H}_{2} \mathrm{O}_{2}$ $(30 \%)$. The reaction was terminated $5 \mathrm{~min}$ after the addition of $100 \mu \mathrm{L}$ of enzyme extract to $3 \mathrm{~mL}$ of the reaction mixture. The change in absorbance of $\mathrm{H}_{2} \mathrm{O}_{2}$ as a consequence of CAT activity was measured using a UVvisible spectrophotometer at $240 \mathrm{~nm}$, with a complete reaction mixture lacking enzyme extract used as a blank. A reduction in absorbance of 0.1 per min was defined as a one unit of CAT activity.

POD activity was assayed according to the method described by Zhang (1990) with slight modification. The reaction mixture contained $100 \mathrm{~mL}$ of phosphate buffer $(0.2$ $M, \mathrm{pH} 6.0)$ and $56 \mu \mathrm{L}$ of guaiacol. The reaction was terminated $5 \mathrm{~min}$ after the addition of $100 \mu \mathrm{L}$ of enzyme extract to $3 \mathrm{~mL}$ of reaction mixture. The change in absorbance was measured spectrophotometrically at 470 $\mathrm{nm}$, with a complete reaction mixture lacking enzyme extract used as a blank. An increase in absorbance of 0.1 per min was defined as one unit of POD activity.

The $\mathrm{O}_{2}^{--}$was determined using the hydroxylamine method (Wang and Luo 1990). The reaction mixture contained $0.5 \mathrm{~mL}$ of leaf extract, $0.5 \mathrm{~mL}$ of phosphate buffer
(50 $\mathrm{m} M$ ) and $1 \mathrm{~mL}$ of hydroxylamine hydrochloride (10 $\mathrm{m} M)$. An equal volume of trichloromethane to the reaction mixture was used to extract chlorophyll by placing in a water bath at $25^{\circ} \mathrm{C}$ for $1 \mathrm{~h}$. The resulting mixture was added to $1 \mathrm{~mL}$ of $p$-aminobenzoic acid $(17 \mathrm{mM})$ and $1 \mathrm{~mL}$ of $\alpha$ naphthylamine $(7 \mathrm{mM})$. The reaction was terminated after $20 \mathrm{~min}$ at $25^{\circ} \mathrm{C}$, and following centrifugation at $3000 \times g$ for $3 \mathrm{~min}$, the red aqueous phase was collected to determine the absorbance at $530 \mathrm{~nm}$. A complete reaction mixture lacking leaf extract was used as a blank.

MDA content was determined using the thiobarbituric acid (TBA) colorimetric method described by $\mathrm{Li}$ et al. (2000). To initiate the reaction, $1.5 \mathrm{~mL}$ of $0.5 \%$ TBA was added to $1.5 \mathrm{~mL}$ of leaf supernatant. The mixture was boiled for $10 \mathrm{~min}$ and then cooled in an ice bath. After centrifugation at $10000 \times g$ for $10 \mathrm{~min}$, the absorbance of the supernatant was recorded at 600,532 , and $450 \mathrm{~nm}$.

Soluble protein content was determined using the Coomassie brilliant blue method described by $\mathrm{Li}$ et al. (2000), with slight modification. The reaction mixture contained $0.1 \mathrm{~mL}$ of leaf extract, $0.9 \mathrm{~mL}$ of distilled water, and $5 \mathrm{~mL}$ of Coomassie brilliant blue, the absorbance was recorded at $595 \mathrm{~nm}$ after $2 \mathrm{~min}$, with a mixture lacking leaf extract used as a blank. The soluble protein content was calculated using bovine serum albumin as a standard.

\section{Gene expression analysis}

Total RNA was extracted from the leaves of five individual plants using a Trizol kit, according to the manufacturer's instructions. Total RNA $(2 \mu \mathrm{g})$ was reverse transcribed using a FastQuant RT Kit (Tiangen Biotech) after treatment with DNase I (TaKaRa) to remove contaminating genomic DNA. Reverse-transcription quantitative PCR was performed using a SYBR Green I PCR kit (TaKaRa), using HIS2 as a reference gene. Each assay was repeated three times, and specific primers were designed using the online tools provided by the National Center for Biotechnology Information (Table 1).

\section{Statistical analyses}

The data obtained were analysed using IBM S.P.S.S. Statistics 20. Significant differences between the means (average of at least three replicates) were compared using Duncan's multiple range tests at the $P<0.05$ level. Figures were prepared using GraphPad Prism 7.

\section{Results}

\section{Accumulation of ROS during natural senescence}

ROS, such as $\mathrm{H}_{2} \mathrm{O}_{2}$ and $\mathrm{O}_{2}{ }^{--}$, are generated in tissues and cells during normal metabolism and under conditions of adverse stress. Similar trends were noted in the $\mathrm{H}_{2} \mathrm{O}_{2}$ content of Z1 and JD74 after flowering, reaching a 
Wang et al. / Intl J Agric Biol, Vol 25, No 2, 2021

Table 1: Sequences of primers used for RT-qPCR

\begin{tabular}{|c|c|c|c|c|c|}
\hline \multirow[t]{2}{*}{ Gene } & \multicolumn{2}{|c|}{ Primer pairs } & \multirow{2}{*}{$\begin{array}{l}\text { Products } \\
\text { Length (bp) }\end{array}$} & \multirow[t]{2}{*}{ GO - function } & \multirow[t]{2}{*}{ Reference } \\
\hline & Forward primer & Reverse primer & & & \\
\hline$M n-S O D$ & 5'- & 5'- CCAGTGCGCCATAGTCGTAA- & 103 & superoxide dismutase activity [Mn] & Lu et al. (2020) \\
\hline Glyma.06G144500 & GCGAAGCCCATAATCGGAGT-3' & $3^{\prime}$ & & (EC:1.15.1.1), mitochondria & \\
\hline $\mathrm{Fe}-\mathrm{SODI}$ & 5'- GCCATTTGCCCAATTGTGTG- & 5'- CCATTGCAGCATCCCAAGAC- & 145 & superoxide dismutase activity $[\mathrm{Fe}]$ & Lu et al. (2020) \\
\hline Glyma.20G050800 & $3^{\prime}$ & $3^{\prime}$ & & (EC:1.15.1.1), chloroplastic & \\
\hline $\mathrm{Fe}-\mathrm{SOD} 2$ & 5 '- & 5'- TAATCACGGCGCTGGTTCTG- & 118 & superoxide dismutase activity $[\mathrm{Fe}]$ & Lu et al. (2020) \\
\hline Glyma.02G087700 & 'TGGTGAAGACTCCCAATGCT-3' & $3^{\prime}$ & & (EC:1.15.1.1), chloroplastic & \\
\hline $\mathrm{Chl} \mathrm{Cu} / \mathrm{Zn}-\mathrm{SOD}$ & 5'- CTTCCCAGCTCCTCAATCCA- & 5'- TGGGCCGTTGTCTTGTTGTT-3' & 121 & superoxide dismutase activity $[\mathrm{Cu}-$ & Lu et al. (2020) \\
\hline Glyma.12G178800 & $3^{\prime}$ & & & Zn] (EC:1.15.1.1), chloroplastic-like & \\
\hline Cyt $\mathrm{Cu} / \mathrm{Zn}-\mathrm{SOD}$ & 5 - & $5+$ & 106 & superoxide dismutase activity $[\mathrm{Cu}-$ & Lu et al. (2020) \\
\hline Glyma.19G240400 & CGAGAATCGTCATGCTGGTG-3' & GGAGTTTGGTCCAGTGAGAGG-3' & & Zn] (EC:1.15.1.1), cytoplasm & \\
\hline $\operatorname{Per} \mathrm{Cu} / \mathrm{Zn}$-SOD & 5'- & 5'- GCCCGATGATACCACATGCT- & 182 & superoxide dismutase activity $[\mathrm{Cu}-$ & Lu et al. (2020) \\
\hline Glyma.16G153900 & CCCTGATGGAGTTGCTGAGA-3' & $3^{\prime}$ & & $\mathrm{Zn]}$ (EC:1.15.1.1), peroxisome-like & \\
\hline CAT1 & 5 '- & 5'- AGACTTTTCGCCAGAGGTGG- & 104 & (EC:1.11.1.6), & Yang et al. (2019) \\
\hline Glyma.17G261700 & GGCATATGGATGGCTTCGGT-3' & $3^{\prime}$ & & peroxisome & \\
\hline CAT3 & $5 '-$ & 5'- GAGCATGGACAACACGTTCG- & 136 & catalase activity & Yang et al. (2019) \\
\hline Glyma.14G223500 & GGTGCTCCCATCTGGAACAA-3' & $3^{\prime}$ & & peroxisome & \\
\hline CAT5 & 5'- CCATCCAGCGCCTTCAATTC- & 5'- GCATGGACAACACGTTCTGG- & 176 & catalase activity (EC:1.11.1.6) & Yang et al. (2019) \\
\hline Glyma.06G017900 & $3^{\prime}$ & $3^{\prime}$ & & & \\
\hline APX6 & 5'- TTCAGTTGGCTGGTGCTACA- & 5'- AGGGCATTGTTCAGGTCCAG- & 98 & L-ascorbate & Homologous with the \\
\hline Glyma.04G248300 & $3^{\prime}$ & $3^{\prime}$ & & $\begin{array}{l}\text { (EC:1.11.1.11), } \\
\text { chloroplastic/mitochondrial }\end{array}$ & $\begin{array}{l}\text { Arabidopsis ATlG77490, } \\
\text { Maruta et al. (2012) }\end{array}$ \\
\hline$A P X 7$ & 5 '- & 5'- CAACCATTGCACTGTCCAGG- & 124 & L-ascorbate peroxidase & Homologous with the \\
\hline Glyma.06G114400 & ATCTGGTGCACACACACTGG-3' & $\sigma$ & & $\begin{array}{l}\text { (EC:1.11.1.11), } \\
\text { chloroplastic/mitochondrial }\end{array}$ & $\begin{array}{l}\text { Arabidopsis ATlG77490, } \\
\text { Maruta et al. (2012) }\end{array}$ \\
\hline$A P X 2$ & 5'- ACAACGGTCTTGACATCGCT- & 5'- GTGACCTCAACGGCAACAAC- & 112 & L-Ascorbate peroxidase & Homologous with the \\
\hline Glyma.12G073100 & 3 & $3^{\prime}$ & & $(\mathrm{EC}: 1.11 .1 .11)$ & $\begin{array}{l}\text { Arabidopsis ATlG07890, } \\
\text { Jiang et al. }(2017)\end{array}$ \\
\hline$A P X 3$ & 5 '- & 5'- TTGTTGGCGCCGTGAGAATA- & 88 & L-Ascorbate peroxidase & Arai et al. (2008) \\
\hline Glyma.12G032300 & ATGCCGGAACTTACGATGCT-3' & $3^{\prime}$ & & (EC:1.11.1.11) & \\
\hline MDHAR2 & $5 '-$ & 5'- GGAGCAACTGGTTCATCGGA- & 108 & Monodehydroascorbate & Homologous \\
\hline Glyma.16G073100 & TGTGATTCTTGGAGGAGGCG-3' & $3^{\prime}$ & & activity, peroxisomal & $\begin{array}{l}\text { Arabidopsis AT3G27820, } \\
\text { Eastmond (2007) }\end{array}$ \\
\hline MDHARI & 5 '- & 5'- GAGGCTGGACCTTAGCAACT- & 137 & Monodehydroascorbate & Homologous with the \\
\hline Glyma.11G209100 & AGACAACAATCCTGCGTCGT-3' & $3^{\prime}$ & & activity & $\begin{array}{l}\text { Arabidopsis AT3G52880, } \\
\text { Eltayeb et al. }(2007)\end{array}$ \\
\hline DHAR4 & 5 - & 5'- ATCCCACGGAGGCAAATTCA- & 105 & DHAR class & Homologous with the \\
\hline Glyma.20G240300 & 'TTGATGGCAAATGGGTGGCT-3' & $3^{\prime}$ & & transferase activity & $\begin{array}{l}\text { Arabidopsis ATlG75270, } \\
\text { Rahantaniaina et al. (2017) }\end{array}$ \\
\hline DHAR3 & 5 & 5'- TCCTGTGGTTGTGCACTTGT-3' & 162 & DHAR class glutathione & Homologous with the \\
\hline Glyma.11G216400 & $\begin{array}{l}\text { TGCAGCTGACCTATCACTTGG- } \\
3^{\prime}\end{array}$ & & & transferase activity & $\begin{array}{l}\text { Arabidopsis AT5G16710, } \\
\text { Noshi } \text { et al. (2016) }\end{array}$ \\
\hline & $5 '-$ & 5'- TGCTTGAGAGCCCGACTTAC- & 105 & Glutathione & Homologous with the \\
\hline Glyma.02G141800 & GTAGGCATTCACCCAAGTGC-3' & & & (EC:1.8.1.7) & $\begin{array}{l}\text { Arabidopsis AT3G54660, } \\
\text { Marty et al. (2019) }\end{array}$ \\
\hline
\end{tabular}

minimum at 14 days after flowering (DAF) and then showing a continual increase (Fig. 1a). Notably, we detected a significant difference in the $\mathrm{H}_{2} \mathrm{O}_{2}$ content of $\mathrm{Z1}$ and JD74 from 29 to $55 \mathrm{DAF}$, during which time $\mathrm{H}_{2} \mathrm{O}_{2}$ accumulation was higher in JD74 than in Z1, indicating the earlier commencement of leaf senescence in JD74 than in Z1. In both varieties, the $\mathrm{O}_{2}{ }^{-}$content increased rapidly after 42 DAF (Fig. 1b), and it had increased by 329 and $167 \%$ at 55 DAF compared with that at anthesis in JD74 and Z1, respectively. These results accordingly indicated that ROS accumulation in the leaves of $\mathrm{Z1}$ was less pronounced than that in JD74. In contrast, with the exception of the final sampling time point (68 DAF), MDA content, which is an indicator of membrane oxidative damage, was higher in $\mathrm{Z1}$ during the course of leaf senescence (Fig. 1c).

\section{Changes in antioxidant enzymatic activities in natural senescence}

SOD functions are the dismutation of $\mathrm{O}_{2}^{--}$to yield $\mathrm{H}_{2} \mathrm{O}_{2}$ and molecular oxygen. With the exception of a slight increase at 36 DAF, SOD activity showed a downward trend in JD74
(Fig. 2a) and was $79.7 \%$ lower at maturity than at anthesis. In Z1, SOD activity showed a rapid increase after 21 DAF, peaked at $42 \mathrm{DAF}$, and was $31.9 \%$ lower at maturity than at anthesis. Moreover, after 29 DAF, SOD activity was significantly higher in Z1 than in JD74.

In both soybean varieties, CAT activity reached the maximum at $29 \mathrm{DAF}$ and thereafter underwent a gradual decline (Fig. 2b). During early senescence, CAT activity was higher in Z1 than in JD74, and at the final sampling time point (68 DAF), the leaves of $\mathrm{Z1}$ retained weak CAT activity, whereas no CAT activity was detected in JD74. This may explain why the leaves of JD74 turned yellow and died.

POD plays dual roles, and its activity can be both beneficial and detrimental to plants. Although it protects cells from oxidative damage and eliminates $\mathrm{H}_{2} \mathrm{O}_{2}$, it is also involved in chlorophyll degradation and ROS accumulation during senescence and accelerates the peroxidation of cell membrane lipids. Consequently, high POD activity can be harmful to cells and tissues. In both soybean varieties, POD activity peaked at $56 \mathrm{DAF}$ (the end of the filling stage) (Fig. 2c). Notably, however, POD activity was higher in $Z 1$ after flowering, particularly during late senescence, and this high 

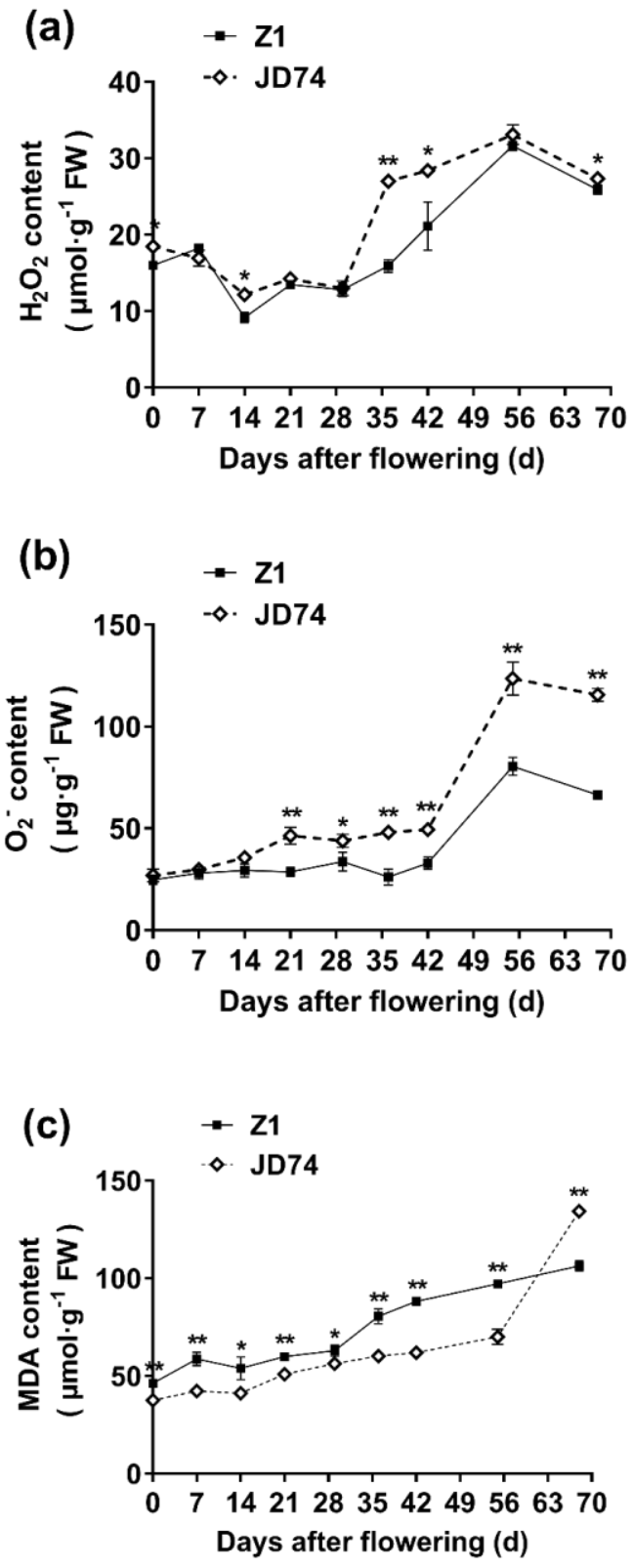

Fig. 1: Changes of $\mathrm{H}_{2} \mathrm{O}_{2}$ content (a), $\mathrm{O}_{2}^{-}$content (b), and MDA content (c) in both varieties after flowering. The error bars indicate SD of data from three replicates. *, $P<0.05$; **, $P<0.01$

POD activity may be responsible for the high MDA levels observed in Z1.

\section{Comparison of antioxidative competence under dark- induced senescence}

To further elucidate the characteristics of ROS accumulation during leaf senescence induced by DT, we grew whole plants of both varieties at the V2 phase (fully expanded second ternately compound leaves) in darkness for 13 days. The colour of JD74 leaves changed after 6 days of DT, and

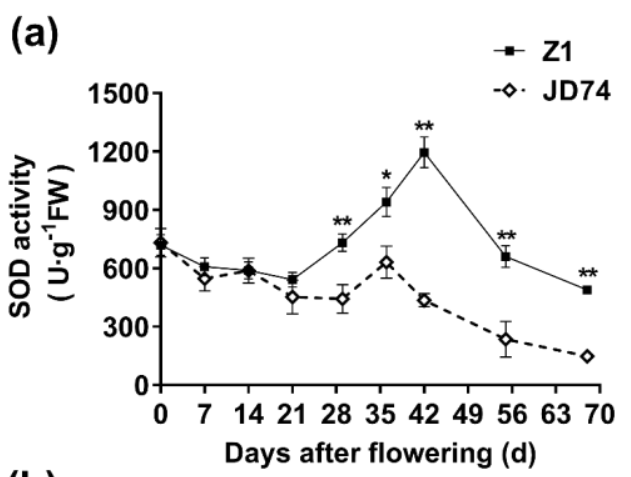

(b)
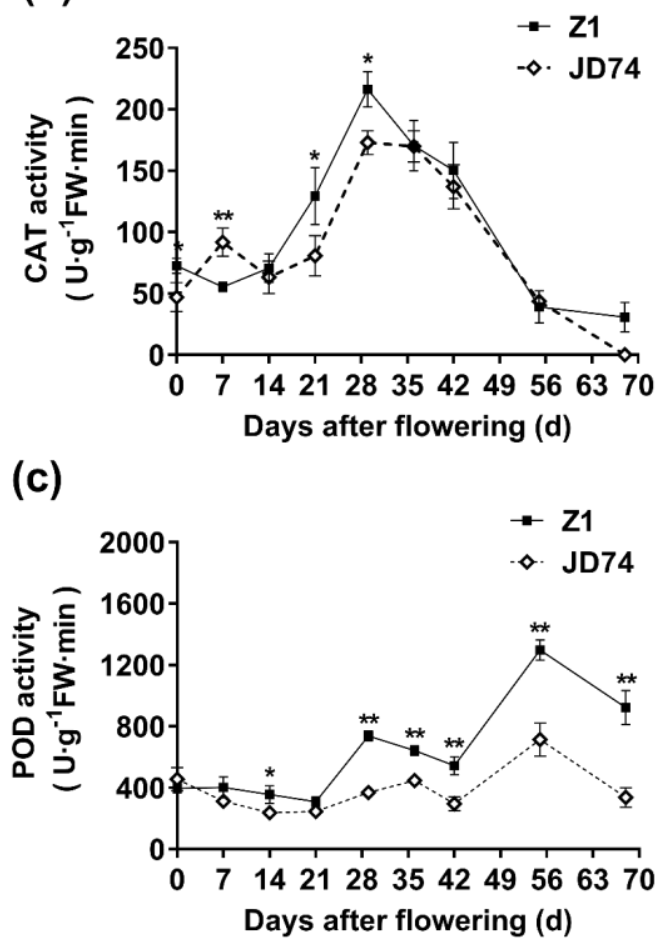

Fig. 2: Changes of antioxidant enzyme activity in both varieties after flowering. (a) SOD activity, (b) CAT activity, (c) POD activity. The error bars indicate SD of data from three replicates. $*, P<0.05 ; * *, P<0.01$

by day 13 , the leaves had turned completely yellow (Fig. 3a). In contrast, the leaves of Z1 plants maintained their original green colour. Accordingly, although the chlorophyll content of Z1 remained unaffected by DT, it underwent a continual reduction in JD74 (Fig. 3b).

When grown in darkness, Z1 plants showed a continual increase in the soluble protein content over the course of the 13 days of DT, whereas the content declined in JD74 (Fig. 4a). In both varieties, however, there was a continual increase in $\mathrm{O}_{2}{ }^{-}$content, although the rate of increase was more rapid in Z1 than in JD74, particularly during the latter stages of DT (Fig. 4b). Under normal growth conditions, MDA content was low in JD74 but increased by 1.57 -fold after 6 days of DT, whereas only a 
(a)

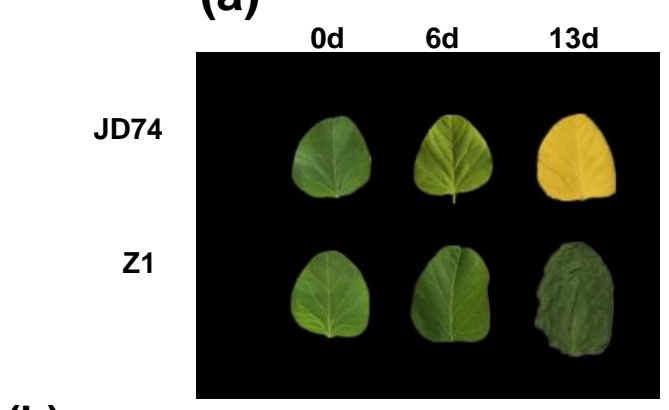

(b)

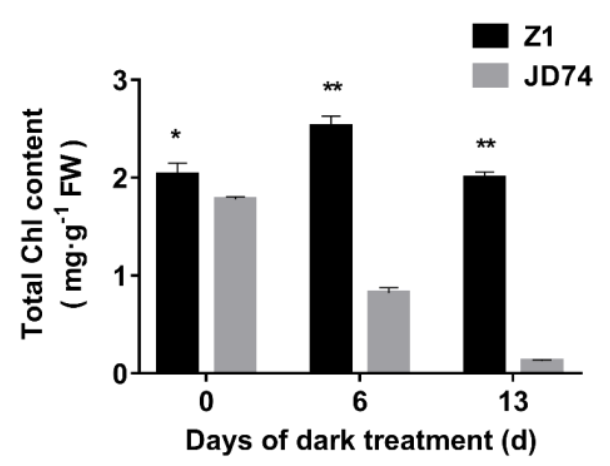

Fig. 3: Comparisons of stay-green phenotype (a) and chlorophyll content (b) among Z1 and JD74 after dark treatment. (a) Thirteen days after dark treatment, JD74 leaf turned completely yellow, whereas the leaf of $\mathrm{Z} 1$ continued maintained its green colour. (b) The chlorophyll content of Z1 was not significantly impacted under DT, but it decreased continually in JD74. The error bars indicate SD of data from three replicates. ${ }^{*}, P<0.05$; **, $P<0.01$

0.47-fold increase was detected in Z1 (Fig. 4c). During the 13 days of DT, a slight increase was noted in the MDA content of JD74 plants, whereas Z1 plants showed a continual increase. These observations indicated severe oxidative damage to the membrane system of JD74 after 6 days of DT, whereas Z1 was more tolerant to dark stress.

In response to DT, we detected differences in the activities of antioxidant enzymes in the two varieties (Fig. 5). Although we observed a continual increase in the activities of SOD, POD, and CAT in Z1 (Fig. 5a, b, and c, respectively), differing responses were detected in JD74. There was a significant reduction in the SOD activity (by $36.9 \%$ ) in JD74 after 6 days of DT (Fig. 5a), whereas POD activity increased after 6 days of DT, but decreased thereafter (Fig. 5b). The CAT activity of JD74 showed a continual increase, with the rate of increase being higher than that in Z1 during the final stage of DT (Fig. 5c).

\section{Expression of antioxidant enzyme-related genes during natural senescence}

For both soybean genotypes, we performed reversetranscription fluorescence quantitative PCR analysis to investigate the expression patterns of antioxidant enzyme- (a)

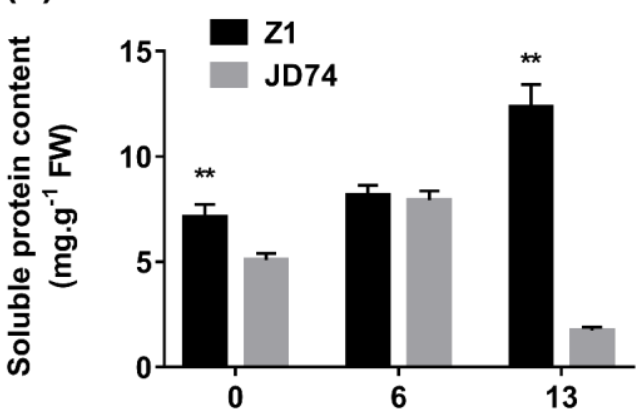

(b)

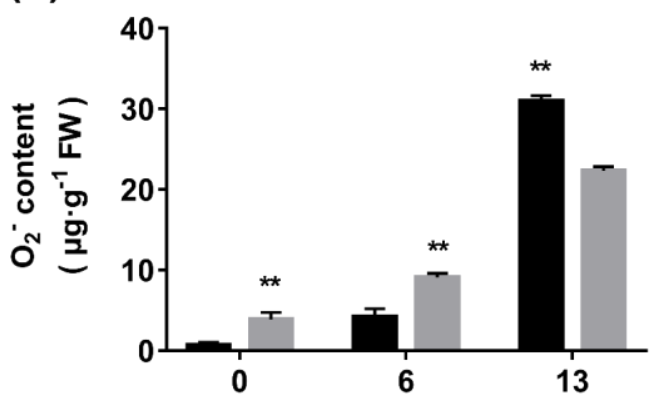

(c)

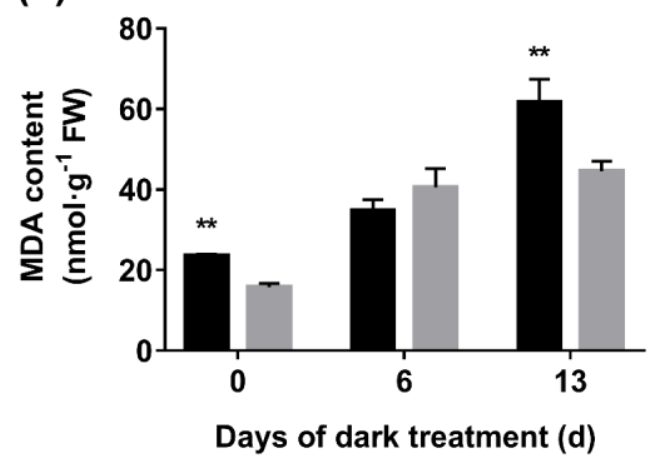

Fig. 4: Changes of soluble protein (a), $\mathrm{O}_{2}^{-}(\mathbf{b})$, and MDA (c) content of the leaves of both varieties under dark treatment. The error bars indicate SD of data from three replicates. ${ }^{*}, P<0.05$; **, $P<0.01$

related genes, the results of which are presented in Figs. 6-9 and are described below.

\section{SOD isogenes}

Six genes encoding the SOD isoenzymes $\mathrm{Mn}-\mathrm{SOD}, \mathrm{Fe}$ SOD1, Fe-SOD2, Chl Cu/Zn-SOD, peroxisome Cu/Zn-SOD, and cytosolic $\mathrm{Cu} / \mathrm{Zn}-\mathrm{SOD}$, were selected by homologous comparison with the Arabidopsis thaliana genome (Table 1). Certain differences were noted in the expression levels of these isogenes at anthesis (Fig. 6a): in both varieties, there was a high expression of $M n-S O D$ and $C h l C u / Z n-S O D$. However, although we initially observed similar patterns of 
(a)

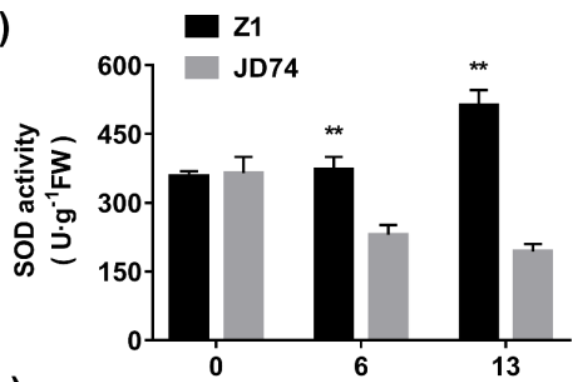

(b)

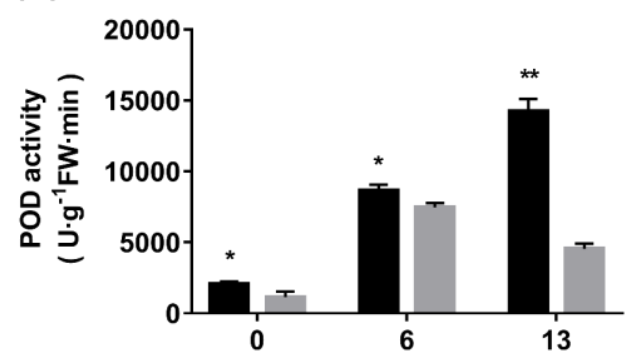

(c)

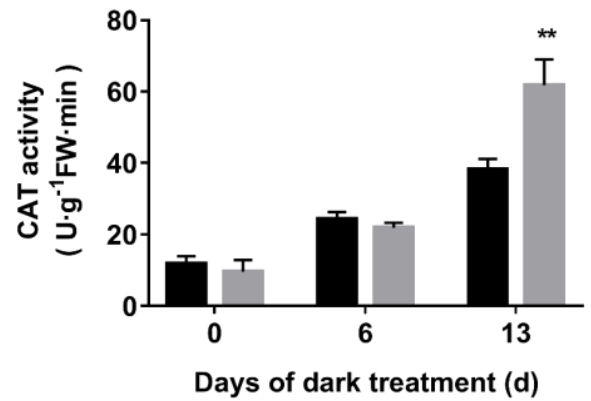

Fig. 5: Changes of antioxidant enzyme activity in both varieties under dark treatment. (a) SOD activity, (b) POD activity, (c) CAT activity. The error bars indicate SD of data from three replicates. $*, P<0.05 ; * *, P<0.01$

$M n$-SOD expression in the two varieties, the expression level was higher in Z1 than in JD74 from anthesis to maturity (Fig. 6b). The levels of $\mathrm{Fe}$-SODI and $\mathrm{Fe}$-SOD2 tended to be very low at anthesis (Fig. 6a), whereas their expression peaked during the late and mid-phase of senescence, respectively (Fig. 6c and d). At most time points, however, the expression of both genes was higher in Z1 than in JD74 (Fig. 6c and d). Although we detected no difference between Z1 and JD74 with respect to $\mathrm{Chl} C \mathrm{Cu} / \mathrm{Zn}$ $S O D$ expression at anthesis (Fig. 6a), we found that whereas Chl Cu/Zn-SOD expression was stable in Z1 after $29 \mathrm{DAF}$, it was suppressed in JD74 (Fig. 6e). Both cytosolic and peroxisome $\mathrm{Cu} / \mathrm{Zn}$-SOD showed up-regulated expression during the mid-stage of leaf senescence (Fig. $6 \mathrm{f}$ and g), although the degree of increase was greater in JD74 and the duration of increase was longer in Z1, particularly in the case of cytosolic Cu/Zn-SOD. Collectively, the aforementioned observations indicate that the expression of $S O D$ isogenes varies both temporally and spatially during (a)

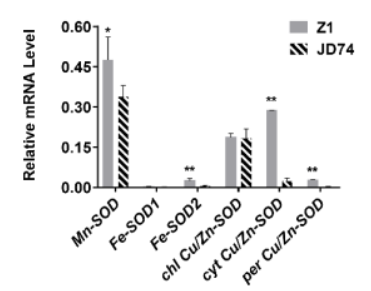

(c)

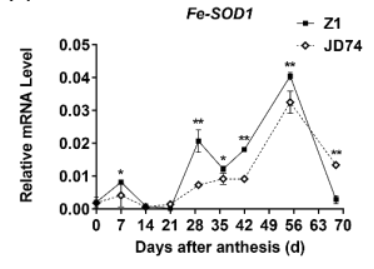

(e)

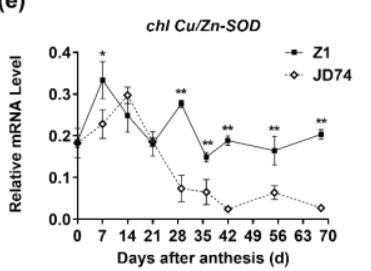

(g)

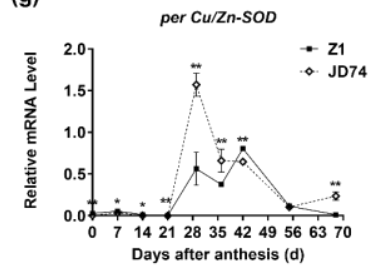

Fig. 6: Differences of SOD isozyme gene expression levels in the leaves of both varieties after flowering. (a) The comparison of six $S O D$ isogene expressions at anthesis. We observed that the expression levels of $\mathrm{Mn}$-SOD, $\mathrm{Fe}$-SOD2, cyt Cu/Zn-SOD, and per $\mathrm{Cu} / \mathrm{Zn}$-SOD were significantly higher in Z1 than in JD74. (b) Relative expression level of $M n-S O D$. (c) Relative expression level of $\mathrm{Fe}$-SOD1. (d) Relative expression level of $\mathrm{Fe}$-SOD2. (e) Relative expression level of chl $\mathrm{Cu} / \mathrm{Zn}-\mathrm{SOD}$. (f) Relative expression level of $c y t C u / Z n-S O D$. (g) Relative expression level of per $C u / Z n-S O D$. The error bars indicate SD of data from three replicates. ${ }^{*}, P<0.05$; **, $P<0.01$

leaf senescence. It can, thus, be speculated that the coordinated activity of these genes contributes to the accumulation and metabolism of ROS in different subcellular structures.

\section{CAT isogenes}

At anthesis, the expression of CAT1 and CAT3 was found to be significantly higher in JD74 than in Z1, whereas that of CAT5 was significantly higher in Z1 (Fig. 7a). After flowering, we observed similar differences in the 

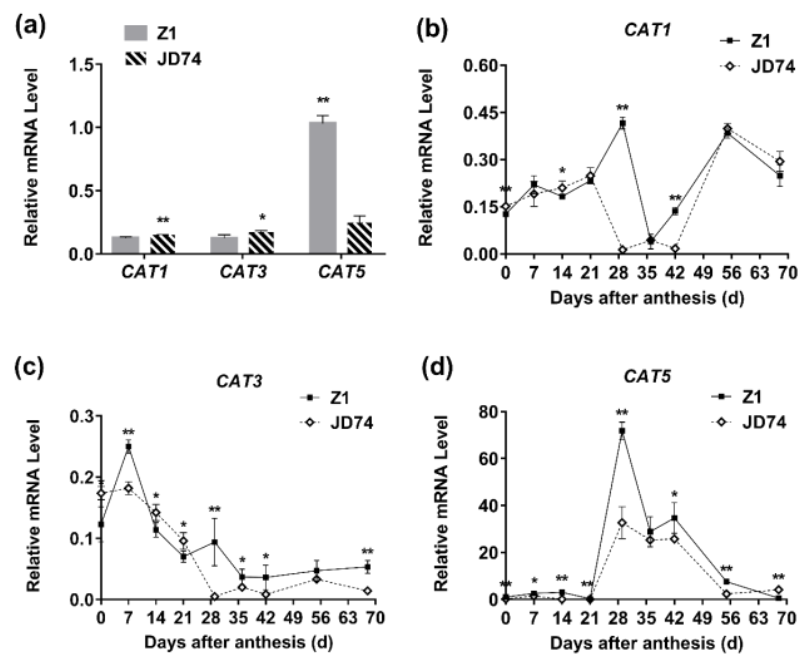

Fig. 7: Differences of CAT isozyme gens expression levels in the leaves of both varieties after flowering. (a) Comparison of three CAT isogene expressions at anthesis. CAT5 in Z1 showed the highest expression level at anthesis. (b) Relative expression level of CAT1. (c) Relative expression level of CAT2. (d) Relative expression level of $C A T 3$. The error bars indicate SD of data from three replicates. *, $P<0.05$; $* *, P<0.01$

expression CAT1, CAT3, and CAT5 in both varieties (Fig. $7 \mathrm{~b}$-d). CAT5 was up-regulated from 21 to $55 \mathrm{DAF}$, and its expression was higher in Z1 than in JD74; in contrast, CAT1 was significantly down-regulated during these periods, although the duration was longer in JD74. In both varieties, CAT3 expression was continually down-regulated after 7 DAF, indicating that it is inhibited during leaf senescence. However, after $29 \mathrm{DAF}$, the expression of this isogene was significantly higher in Z1 than in JD74.

\section{ASH-GSH cycle-related genes}

A comparison of the expression patterns of $A P X$ isozyme genes at anthesis is presented in Fig. 8a. Among the isogenes, the expression of $A P X 7$ was the highest in both varieties, and that of $A P X 7$ and $A P X 3$ was significantly higher in Z1 than in JD74. Similarly, we observed comparable expression patterns of four $A P X$ isogenes in the two genotypes from anthesis to maturity. The expression of APX6 was suppressed after 7 DAF (Fig. 8c), whereas that of $A P X 7$ was up-regulated after 21 DAF (Fig. 8d). Furthermore, in JD74, APX2 expression remained suppressed until 42 DAF, but thereafter showed continual up-regulation. In contrast, APX2 expression showed the opposite pattern in $\mathrm{Z1}$, being initially up-regulated and subsequently downregulated (Fig. 8e). In both varieties, the expression of $A P X 3$ remained consistently suppressed (Fig. 8f).

At anthesis, the expression levels of MDHARI and $D H A R 3$ were found to be significantly higher in $\mathrm{Z} 1$ than in JD74 (Fig. 9a and d). The expression patterns of these genes were, nevertheless, highly similar in the two varieties, with
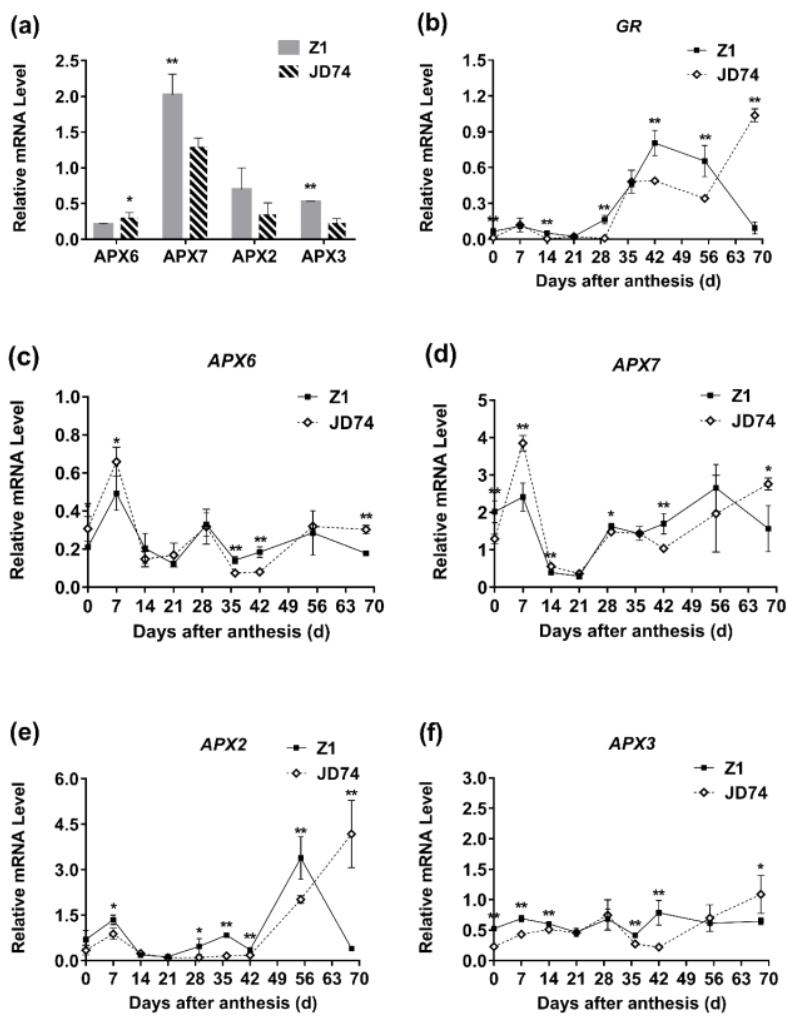

Fig. 8: Expression levels of APX isozyme genes in the leaves of both varieties after flowering. (a) Comparison of the expression of four $A P X$ isogenes at anthesis. The expression levels of $A P X 7$ and $A P X 6$ were significantly higher in Z1 than in JD74. (b) Relative expression level of $G R$. (c) Relative expression level of APX6 (d) Relative expression level of $A P X 7$ (e) Relative expression level of $A P X 2$ (f) Relative expression level of $A P X 3$. The error bars indicate SD of data from three replicates. *, $P<0.05$; **, $P<0.01$

both being strongly up-regulated from $21 \mathrm{DAF}$, and the degree of increase being higher for MDHARl (Fig. 9c and f). The expression levels of MDHARI and DHAR3 were higher in Z1 than in JD74 from 29 to 55 DAF (Fig. 9c and f), whereas MDHAR2 and DHAR4 were inhibited from 29 to $42 \mathrm{DAF}$ in JD74, a longer period than that observed in $\mathrm{Z1}$ (Fig. 9b and e). We also found that the pattern of $G R$ expression was similar to that of MDHAR1 and DHAR3 (Fig. 8b, Fig. 9c and f).

\section{Discussion}

Leaf senescence is associated with an elevated production of ROS and subsequent oxidative damage (Checovich et al. 2016; Pilarska et al. 2017; Shi et al. 2019). The effective elimination of ROS by the antioxidant protection system of plants enables leaves to respond more effectively to different environmental stresses, oxidative damage, and cell apoptosis (Petrov et al. 2015). Inhibition of leaf senescence and a prolonged leaf stay-green period are attributed to the high activities of antioxidant enzymes (Nawaz et al. 2013; 

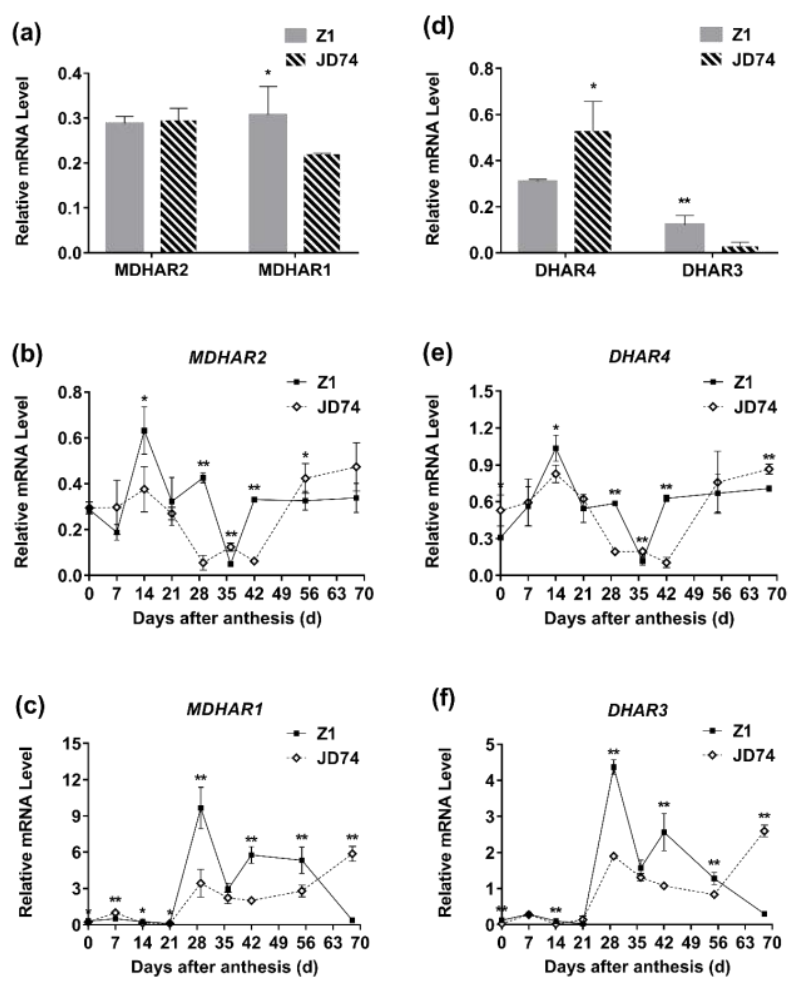

Fig. 9: Expression levels of MDHAR and DHAR isozyme genes in the leaves of both varieties after flowering. (a) Comparison of expression levels of two MDHAR isogenes at anthesis. (b) Relative expression level of MDHAR2. (c) Relative expression level of MDHARI (d) Comparison of expression of two DHAR isogenes at anthesis. (e) Relative expression level of DHAR4. (f) Relative expression level of DHAR3. The error bars indicate SD of data from three replicates. ${ }^{*}, P<0.05 ; * *, P<0.01$

Wu et al. 2018) and the stay-green genotype has been shown to be associated with an actively regulated mechanism for coping with ROS under biotic or abiotic stress without causing severe membrane damage (Farooq et al. 2009; Li et al. 2017; Pal et al. 2020). In the wheat staygreen mutant tasgl, accumulation of $\mathrm{O}_{2}^{--}$and $\mathrm{H}_{2} \mathrm{O}_{2}$ in the flag leaves is lower than that in WT plants (Tian et al. 2013) and the activities of SOD, CAT, and POD are higher than those in the WT under normal conditions (Wang et al. 2016). Furthermore, during the grain-filling stage, the activities of antioxidant enzymes in the leaves of stay-green wheat decrease at slower rates than those in the leaves of a common variety of wheat (Xue et al. 2010). These findings are all consistent with the results obtained in the present study. During the mid- and late stages of leaf senescence in the field, the activities of antioxidant enzymes in Z1 were significantly higher than those of JD74, thereby promoting a reduction in the accumulation of $\mathrm{H}_{2} \mathrm{O}_{2}$ and $\mathrm{O}_{2}^{-{ }^{-}}$. Furthermore, when subjected to DT, we found that the balance of internal reactive oxygen metabolism in Z1 leaves remained essentially unimpaired, and the leaves showed no obvious senescence traits. Collectively, these results indicate that Z1 has a stronger ability than JD74 to eliminate ROS and delay leaf senescence. Furthermore, we found that POD activity, which may result in oxidative damage during leaf senescence, was higher in Z1 during early senescence and may have resulted in a higher MDA content, whereas during late senescence, MDA content was higher in JD74. Accordingly, it is plausible that the photosynthetic apparatus in JD74 was seriously damaged, thereby leading to a surplus of residual light energy, which induced ROS accumulation and accelerated membrane lipid peroxidation.

Genome-wide identification of SOD family genes and analyses of their transcriptional characteristics have been performed for a range of different species (Feng et al. 2016; Zhou et al. 2017; Verma et al. 2019) and have revealed that $S O D s$ have diverse expression patterns in different plant tissues and play different roles in response to different abiotic stresses (Zhou et al. 2017; Jiang et al. 2019). In the present study, we found that among these genes, the expression of $M n-S O D$ was the highest at anthesis but decreased concomitant with the accumulation of $\mathrm{O}_{2}{ }^{-}$during early leaf senescence. However, the decrease was attenuated in Z1 compared with that in JD74, and this might be the main reason for the higher SOD activity in $\mathrm{Z} 1$. Li (2014) reported that repression of the Mn-SOD gene is one of the primary factors underlying a reduction in total SOD activity in rice. $\mathrm{Cu} / \mathrm{Zn}$-SOD also plays an important antioxidant protective role during leaf senescence, and analysis of the cis-acting elements of $S O D$ promoters has shown that only $\mathrm{Cu} / \mathrm{Zn}-\mathrm{SOD}$ subfamily genes contain defence and stress-responsive elements and that most $\mathrm{Cu} / \mathrm{Zn}$-SOD subfamily genes have higher expression levels in the leaves (Lu et al. 2020). In the present study, we found that both cytosolic $\mathrm{Cu} / \mathrm{Zn}$ $S O D$ and peroxisome $\mathrm{Cu} / \mathrm{Zn}$-SOD were up-regulated at $21 \mathrm{DAF}$, apparently to compensate for the influence of SOD activity caused by a decline in $M n-S O D$ expression, particularly the cytosolic $\mathrm{Cu} / \mathrm{Zn}-\mathrm{SOD}$, which showed manifold up-regulated expression. During leaf senescence, an increase in Cu/Zn-SOD activity is mainly attributable to enhanced cytosolic $\mathrm{Cu} / \mathrm{Zn}$-SOD activity and the expression of its corresponding encoding gene (Wang 2016). We found that the duration of the upregulated expression of cytosolic $\mathrm{Cu} / \mathrm{Zn}$-SOD was longer in Z1 than in JD74, and this may have accordingly promoted an increase in $\mathrm{Cu} / \mathrm{Zn}$-SOD activity. Although in JD74 we observed a suppression of $\mathrm{Chl} \mathrm{Cu} / \mathrm{Zn}$-SOD expression after $28 \mathrm{DAF}$, there was no similar suppression in $\mathrm{Z} 1$, which may have been attributable to the retention of chlorophyll in the latter variety. Furthermore, we observed that among the different $S O D$ isogenes, $\mathrm{Fe}$-SODs were expressed at the lowest levels in the leaves of both varieties, which is consistent with the findings of Lu et al. (2020). Thus, these observations tend to indicate that the stay-green mutation in Z1 contributes to the stability of total SOD activity owing to the higher expression of $M n-S O D, C h l C u / Z n-S O D$, and cytosolic $\mathrm{Cu} / \mathrm{Zn}-\mathrm{SOD}$. However, we found that expression 
of all the $S O D$ isogenes was suppressed in response to a continuous accumulation of ROS, thereby resulting in a reduction in the total SOD enzyme activity.

CAT plays a critical role in the ROS-scavenging process and is involved in activating plant responses to different abiotic stresses. The expression of plant $C A T$ genes is regulated both temporally and spatially (Wang et al. 2019). In Arabidopsis, CAT1 is generated in response to abiotic stress (Wang et al. 2019) and its expression differs in accordance with the concentration of $\mathrm{H}_{2} \mathrm{O}_{2}$. CAT2 is repressed to enhance ROS accumulation and accelerate leaf senescence or in response to $\mathrm{Pb}$ stress (Corpas and Barroso 2017; Guo et al. 2017), whereas CAT3 is mainly activated in response to abscisic acid and oxidative treatments, as well as during senescence (Du et al. 2008). The overexpression of AtCAT3 enhances the tolerance of Arabidopsis plants to drought stress (Zou et al. 2015). In the present study, we analysed the expression of CAT isogenes homologous to those characterised in Arabidopsis. We accordingly found that expression of CAT1 in JD74 was repressed from 29 to $42 \mathrm{DAF}$, the duration of which was longer than that in Z1. $C A T 5$ was up-regulated after $21 \mathrm{DAF}$, and the increase was greater in Z1 than in JD74, whereas the expression of CAT3 was invariably found to be repressed during leaf senescence, although the expression level was still higher in $\mathrm{Z} 1$. These findings, which are consistent with those of previous studies, indicate enhanced CAT activity in Z1.

The ASA-GSH pathway comprises four enzymes, namely, APX, MDHAR, DHAR and GR (Raja et al. 2017) and plays a key role in ROS detoxification by regulating intracellular levels of $\mathrm{H}_{2} \mathrm{O}_{2}$ (Hasanuzzaman et al. 2019; Raja et al. 2020). In higher plants, $\mathrm{H}_{2} \mathrm{O}_{2}$ is produced predominantly in the chloroplasts and peroxisomes, in which APX is widely distributed and reduces $\mathrm{H}_{2} \mathrm{O}_{2}$ to $\mathrm{H}_{2} \mathrm{O}$ via the oxidation of ASA, thereby protecting these structures from oxidative damage (Rohman et al. 2019). The two Chl $A P X$ isogenes $t A P X$ and $s A P X$ are located in the thylakoid membrane and chloroplast stroma, respectively (Qiu et al. 2020), the former of which is highly sensitive to exogenous $\mathrm{H}_{2} \mathrm{O}_{2}$ (in contrast to $\left.s A P X\right)(\mathrm{Li} 2014$ ), and its expression is rapidly suppressed during senescence (Panchuk et al. 2005). Although the expression of peroxisome APX is suppressed irrespective of $\mathrm{H}_{2} \mathrm{O}_{2}$ concentration, cytoplasmic $A P X$ can be induced by exogenous $\mathrm{H}_{2} \mathrm{O}_{2}$ ( $\mathrm{Li} 2014$ ), and in the present study, we found that the expression of $A P X 6$ and $A P X 3$ (peroxisome $A P X$ ) was significantly repressed during leaf senescence, whereas that of $A P X 7$ and $A P X 2$ (cytoplasmic $A P X s$ ) was gradually up-regulated concomitant with $\mathrm{H}_{2} \mathrm{O}_{2}$ accumulation during late senescence. We, therefore, speculate that $A P X 6$ and $A P X 7$ in soybean are homologues of $t A P X$ and $s A P X$, respectively. APX enzymes function cooperatively to eliminate the $\mathrm{H}_{2} \mathrm{O}_{2}$ generated in chloroplasts. During the accumulation of $\mathrm{H}_{2} \mathrm{O}_{2}$ on thylakoid membranes, the expression of $t A P X$ is continuously repressed, and the spread of excess $\mathrm{H}_{2} \mathrm{O}_{2}$ into the chloroplast stroma induces the expression of $s A P X$ (Neill et al. 2002).
The expression of APX3 (peroxisome $A P X$ ) is also continually repressed owing to the large amounts of $\mathrm{H}_{2} \mathrm{O}_{2}$ produced by photorespiration in the peroxisomes, and subsequent entry of the excess $\mathrm{H}_{2} \mathrm{O}_{2}$ into the chloroplasts and cytoplasm via channel proteins (Mittler et al. 2004) induces the expression of $A P X 7(s A P X)$ and $A P X 2$ (cytoplasmic $A P X$ ). In the present study, we found that the expression levels of these four $A P X$ isogenes in $\mathrm{Z} 1$ were significantly higher during filling stages (approximately 36-55 DAF), indicating an enhanced $\mathrm{H}_{2} \mathrm{O}_{2}$-scavenging capacity.

The three remaining key enzymes of the ASA-GSH cycle, MDHAR, DHAR, and GR, are responsible for the reduction of MDHA and DHA and play roles in maintaining the regeneration of ASA and GSH (Rohman et al. 2019). A marked increase in APX activity is concomitant with an increase in ASA levels in maize leaves (Zhang et al. 2014; Rohman et al. 2019), whereas a deficiency in ASA can lead to the passivation or instability of APX enzyme activity (Ishikawa and Shigeoka 2008). In the present study, we detected higher levels of MDHAR, DHAR, and GR expression in $\mathrm{Z1}$ during the filling stages, thereby indicating the enhanced regeneration of ASA and GSH in this variety, which promotes the effective removal of $\mathrm{H}_{2} \mathrm{O}_{2}$ and, consequently, delays leaf senescence. In addition, we observed that the pattern of MDHAR2 expression was similar to that of DHAR4, whereas the pattern of MDHAR1 expression was similar to that of DHAR3, thus, indicating that during leaf senescence, these isogenes function synergistically in the antioxidant process.

\section{Conclusion}

Taken together, the results of the present study indicate that the stay-green variety $\mathrm{Z} 1$ exhibits enhanced antioxidative competence during leaf senescence, which may delay leaf senescence under both natural and dark conditions. We established that the stay-green mutation in Z1 contributes to the stability of total SOD activity via a higher expression of Mn-SOD, Chl Cu/Zn-SOD, and cytosolic Cu/Zn-SOD. The observed higher levels of MDHAR and DHAR expression in $\mathrm{Z} 1$ are considered indicative of an enhanced regeneration of ASA, whereas the subsequent activation and stabilisation of APX enzyme activity mediate the scavenging of $\mathrm{H}_{2} \mathrm{O}_{2}$ and, consequently, contribute to a delay in leaf senescence.

\section{Acknowledgements}

This work was supported by the European Union's Horizon 2020 Programme for Research \& Innovation (grant no. 727312) and the Ministry of Science and Technology of the People's Republic of China (Key projects for intergovernmental cooperation in science and technology innovation, grant no. 2017YFE0111000). We thank Editage (www.editage.cn) for English language editing. 


\section{Author Contributions}

Peng Wang and Siyu Hou contributed to study conceptualization and design. Material preparation and data collection and analysis were performed by Peng Wang and Hongwei Wen. The first draft of the manuscript was written by Peng Wang. Quanzhen Wang and Guiquan Li supervised the research and revised the previous versions of the manuscript. All authors have read and approved the final manuscript.

\section{References}

Arai Y, M Hayashi, M Nishimura (2008). Proteomic analysis of highly purified peroxisomes from etiolated soybean cotyledons. Plant Cell Physiol 49:526-539

Aziz A, Wahid A, Farooq M (2014) Leaf age and seasonality determines the extent of oxidative stress and induction of antioxidants in lemongrass. Pak J Agric Sci 51:659-664.

Blackney MJ, R Cox, D Shepherd, JD Parker (2014). Cloning and expression analysis of Drosophila extracellular $\mathrm{Cu} \mathrm{Zn}$ superoxide dismutase. Biosci Rep 34:851-864

Checovich ML, A Galatro, JI Moriconi, M Simontacchi, J Dubcovsky, GE Santa-María (2016). The stay-green phenotype of TaNAM-RNAi wheat plants is associated with maintenance of chloroplast structure and high enzymatic antioxidant activity. Plant Physiol Biochem 104:257-265

Choudhury FK, RM Rivero, E Blumwald, R Mittler (2017). Reactive oxygen species, abiotic stress and stress combination. Plant $J$ 90:856-867

Corpas FJ, JB Barroso (2017). Lead-induced stress, which triggers the production of nitric oxide (NO) and superoxide anion $\left(\mathrm{O} 2^{-}\right)$in Arabidopsis peroxisomes, affects catalase activity. Nitric Oxide 68:103-110

Dhindsa RS, PP Dhindsa, TA Thorpe (1981). Leaf senescence: Correlated with increased levels of membrane permeability and lipid peroxidation and decreased levels of superoxide dismutase and catalase. J Exp Bot 32:93-101

Du YY, PC Wang, J Chen, CP Song (2008). Comprehensive functional analysis of the catalase gene family in Arabidopsis thaliana. J Integr Plant Biol 50:1318-1326

Eastmond PJ (2007). MONODEHYROASCORBATE REDUCTASE4 is required for seed storage oil hydrolysis and postgerminative growth in Arabidopsis. Plant Cell 19:1376-1387

Eltayeb AE, N Kawano, GH Badawi, H Kaminaka, T Sanekata, T Shibahara, S Inanaga, K Tanaka (2007). Overexpression of monodehydroascorbate reductase in transgenic tobacco confers enhanced tolerance to ozone, salt and polyethylene glycol stresses. Planta 225:1255-1264

Farooq M, Wahid A, Kobayashi N, Fujita D, Basra SMA (2009) Plant drought stress: Effects, mechanisms and management. Agron Sustain Dev 29:185-212

Farooq MA, Niazi AK, Akhtar J, Saifullah, Farooq M, Souri Z, Karimi N, Rengel Z (2019) Acquiring control: The evolution of ROS-induced oxidative stress and redox signaling pathways in plant stress responses. Plant Physiol Biochem 141:353-369.

Feng K, J Yu, Y Cheng, M Ruan, R Wang, Q Ye, G Zhou, Z Li, Z Yao, Y Yang, Q Zheng, H Wan (2016). The SOD gene family in tomato: Identification, phylogenetic relationships, and expression patterns. Front Plant Sci 7; Article 1279

Gill SS, N Tuteja (2010). Reactive oxygen species and antioxidant machinery in abiotic stress tolerance in crop plants. Plant Physiol Biochem 48:909-930

Guo P, Z Li, P Huang, B Li, S Fang, J Chu, H Guo (2017). A tripartite amplification loop involving the transcription factor WRKY75, salicylic acid, and reactive oxygen species accelerates leaf senescence. Plant Cell 29:2854-2870
Huang L, J Jia, X Zhao, M Zhang, X Huang, E Ji, L Ni, M Jiang (2017). The ascorbate peroxidase $A P X 1$ is a direct target of a zinc finger transcription factor ZFP36 and a late embryogenesis abundant protein OsLEA5 interacts with ZFP36 to co-regulate OsAPX1 in seed germination in rice. Biochem Biophys Res Commun 495:339-345

Hussain M, S Farooq, W Hasan, S Allah, M Tanveer, M Farooq, A Nawaz (2018). Drought stress in sunflower: Physiological effects and its management through breeding and agronomic alternatives. Agric Water Manage 201:152-166

Ishikawa T, S Shigeoka (2008). Recent advances in ascorbate biosynthesis and the physiological significance of ascorbate peroxidase in photosynthesizing organisms. Biosci Biotechnol Biochem 72:1143-1154

Jiang L, W Wang, Z Chen, Q Gao, Q Xu, H Cao (2017). A role for APX1 gene in lead tolerance in Arabidopsis thaliana. Plant Sci 256:94-102

Jiang W, L Yang, Y He, H Zhang, W Li, H Chen, D Ma, J Yin (2019). Genome-wide identification and transcriptional expression analysis of superoxide dismutase (SOD) family in wheat (Triticum aestivum). PeerJ 7:94-102

Kusaba M, A Tanaka, R Tanaka (2013). Stay green plants: What do they tell us about the molecular mechanism of leaf senescence? Photosynth Res 117:221-234

Leonowicz G, KF Trzebuniak, P Zimak-Piekarczyk, I Ślesak, B MysliwaKurdziel (2018). The activity of superoxide dismutases (SODs) at the early stages of wheat deetiolation. PLoS One 13; Article e0194678

Li HS, Q Sun, SJ Zhao, WH Zhang (2000). Plant physiology biochemistry principle and experimental technique. Higher Education Press, Beijing, China

Li Q, S Zhong, S Sun, SA Fatima, M Zhang, W Chen, Q Huang, S Tang, P Luo (2017). Differential effect of whole-ear shading after heading on the physiology, biochemistry and yield index of stay-green and nonstay-green wheat genotypes. PLoS One 12; Article e0171589

Li ZW (2014). The expression alteration of various genes related to sugar metabolism in senescing leaves and its antioxidation modulation for esl mutant. Dissertation. Zhejiang University, China

Lu WX, H Duanmu, Y Qiao, X Jin, Y Yu, L Yu, C Chen (2020). Genomewide identification and characterization of the soybean SOD family during alkaline stress. PeerJ 8; Article e8457

Marty L, D Bausewein, C Müller, SAK Bangash, A Moseler, M Schwarzländer, SJ Müller-Schüssele, B Zechmann, C Riondet, J Balk, M Wirtz, R Hell, JP Reichheld, AJ Meyer (2019). Arabidopsis glutathione reductase 2 is indispensable in plastids, while mitochondrial glutathione is safeguarded by additional reduction and transport systems. New Phytol 224:1569-1584

Maruta T, M Noshi, A Tanouchi, M Tamoi, Y Yabuta, K Yoshimura, T Ishikawa, S Shigeoka (2012). $\mathrm{H}_{2} \mathrm{O}_{2}$-triggered retrograde signalling from chloroplasts to nucleus plays specific role in response to stress. J Biol Chem 287:11717-11729

Mhamdi A, G Queval, S Chaouch, S Vanderauwera, F Van Breusegem, G Noctor (2010). Catalase function in plants: A focus on Arabidopsis mutants as stress-mimic models. J Exp Bot 61:4197-4220

Mittler R, S Vanderauwera, M Gollery, FV Breusegem (2004). Reactive oxygen gene network of plants. Trends Plant Sci 9:490-498

Morita S, S Nakatani, T Kosbiba, T Masumura, Y Ogihara, K Tanaka (2011). Differential expression of two cytosolic ascorbate peroxidases and two superoxide dismutase genes in response to abiotic stress in rice. Rice Sci 18:157-166

Nawaz A, Farooq M, Cheema SA, Yasmeen A, Wahid A (2013) Stay green character at grain filling ensures resistance against terminal drought in wheat. Intl J Agric Biol 15:1272-1276

Neill S, R Desikan, A Clarke, RD Hurst, JT Hancock (2002). Hydrogen peroxide and nitric oxide as signalling molecules in plants. J Exp Bot 53:1237-1247

Noshi M, R Hatanaka, N Tanabe, Y Terai, T Maruta, S Shigeoka (2016). Redox regulation of ascorbate and glutathione by a chloroplastic dehydroascorbate reductase is required for high-light stress tolerance in Arabidopsis. Biosci Biotechnol Biochem 80:870-877

Pal R, G Mahajan, V Sardana, B Asthir, BS Chauhan (2020). Performance of dry-seeded rice genotypes under varied soil moisture regimes and foliar-applied hormones. Plants 9:539-556 
Panchuk II, U Zentgraf, RA Volkov (2005). Expression of the APX gene family during leaf senescence of Arabidopsis thaliana. Planta 222:926-932

Petrov V, J Hille, B Mueller-Roeber, TS Gechev (2015). ROS-mediated abiotic stress-induced programmed cell death in plants. Front Plant Sci 6; Article 69

Pilarska M, E Skowron, R Pietra's, K Krupinska, E Niewiadomska (2017). Changes in lipid peroxidation in stay-green leaves of tobacco with senescence-induced synthesis of cytokinins. Plant Physiol Biochem 118:161-167

Porra RJ, WA Thompson, PE Kriedemann (1989). Determination of accurate extinction coefficients and simultaneous equations for assaying chlorophylls $\mathrm{a}$ and $\mathrm{b}$ extracted with four different solvents: Verification of the concentration of chlorophyll standards by atomic absorption spectroscopy. Biochim Biophys Acta 975:384-394

Prochazkova D, RK Sairam, GC Srivastava, DV Singh (2001). Oxidative stress and antioxidant activity as the basis of senescence in maize leaves. Plant Sci 161:765-771

Qiu Y, YV Tay, Y Ruan, KL Adams (2020). Divergence of duplicated genes by repeated partitioning of splice forms and subcellular localization. New Phytol 225:1011-1022

Rahantaniaina MS, S Li, G Chatel-Innocenti, A Tuzet, E IssakidisBourguet, A Mhamdi, G Noctor (2017). Cytosolic and chloroplastic DHARs cooperate in oxidative stress-driven activation of the salicylic acid pathway. Plant Physiol 174:956-971

Raja V, SU Qadir, MN Alyemeni, P Ahmad (2020). Impact of drought and heat stress individually and in combination on physio-biochemical parameters, antioxidant responses, and gene expression in Solanum lycopersicum. 3Biotech 10; Article 208

Raja V, U Majeed, H Kang, KI Andrabi, R John (2017). Abiotic stress: Interplay between ROS, hormones and MAPKs. Environ Exp Bot 137:142-157

Rohman MM, MR Islam, MB Monsur, M Amiruzzaman, M Fujita, M Hasanuzzaman (2019). Trehalose protects maize plants from salt stress and phosphorus deficiency. Plants 8; Article 568

Secenji M, E Hideg, A Bebes, J Gyorgyey (2010). Transcriptional differences in gene families of the ascorbate-glutathione cycle in wheat during mild water deficit. Plant Cell Rep 29:37-50

Shi X, S Xu, D Mu, E Sadeghnezhad, Q Li, Z Ma, L Zhao, Q Zhang, L Wang (2019). Exogenous melatonin delays dark-Induced grape leaf senescence by regulation of antioxidant system and senescence associated genes (SAGs). Plants 8; Article 366

Shigeoka S, T Ishikawa, M Tamoi, Y Miyagawa, T Takeda, Y Yabuta, K Yoshimura (2002). Regulation and function of ascorbate peroxidase isoenzymes. $J$ Exp Bot 53:1305-1319

Shokri-Gharelo R, PM Noparvar (2018). Molecular response of canola to salt stress: Insights on tolerance mechanisms. Peer $J$ 6; Article e4822

Teranishi Y, A Tanaka, M Osumi, S Fukui (1974). Catalase activity of hydrocarbon utilizing candida yeast. Agric Biol Chem 38:1213-1220

Thomas H, CJ Howarth (2000). Five ways to stay green. J Exp Bot 51:329-337

Tian FX, M Zhang, X Wang, YH Chen, W Wang (2015). Antioxidative defence under drought stress in a wheat stay-green mutant. Biol Plantarum 59:123-130
Tian FX, JF Gong, J Zhang, M Zhang, GK Wang, AX Li, W Wang (2013). Enhanced stability of thylakoid membrane proteins and antioxidant competence contribute to drought stress resistance in the tasg1 wheat stay-green mutant. J Exp Bot 64:1509-1520

Verma D, N Lakhanpal, K Singh (2019). Genome-wide identification and characterization of abiotic-stress responsive SOD (superoxide dismutase) gene family in Brassica juncea and B. rapa. BMC Genomics 20; Article 227

Wang AG, GH Luo (1990). Quantitative relation between the reaction of hydroxylamine and superoxide anion radicals in plants. Plant Physiol Commun 6:55-57

Wang FB (2016). Physiological mechanism of leaf senescence formation and its metabolic regulation in premature senescence rice ( $p s f$ ) mutant leaves. Dissertation, Zhejiang University, China

Wang N, Y Zhang, SN Huang, ZY Liu, CY Li, H Feng (2020). Defect in Brnym1, a magnesium-dechelatase protein, causes a stay-green phenotype in an EMS-mutagenized Chinese cabbage (Brassica campestris L. sspp. pekinensis) line. Hortic Res 7:8-18

Wang W, Y Cheng, D Chen, D Liu, M Hu, J Dong, X Zhang, L Song, F Shen (2019). The catalase gene family in cotton: Genome-wide characterization and bioinformatics analysis. Cells 8:86-112

Wang WQ, Q Hao, F Tian, Q Li, W Wang (2016). The stay-green phenotype of wheat mutant tasg1 is associated with altered cytokinin metabolism. Plant Cell Rep 35:585-599

Wang Y, R Branicky, A Noë, S Hekimi (2018). Superoxide dismutases: Dual roles in controlling ROS damage and regulating ROS signalling. J Cell Biol 217:1915-1928

Wu H, J Xiang, Y Zhang, Y Zhang, S Peng, H Chen, D Zhu (2018). Effects of post-anthesis nitrogen uptake and translocation on photosynthetic production and rice yield. Sci Rep 8; Article 12891

Xue H, L Jia, YH Gong, YZ Liu, YH Wu (2010). Study on the stay-green capacity and leaf senescence of winter wheat. Acta Bot Bor-Occident $\operatorname{Sin}$ 30:336-343

Yang Z, A Mhamdi, G Noctor (2019). Analysis of catalase mutants underscores the essential role of CATALASE2 for plant growth and day length-dependent oxidative signalling. Plant Cell Environ 42:688-700

Yoon HS, H Lee, IA Lee, KY Kim, J Jo (2004). Molecular cloning of the monodehydroascorbate reductase gene from Brassica campestris and analysis of its mRNA level in response to oxidative stress. Biochim Biophys Acta 1658:181-186

Zhang K, H Liu, P Tao, H Chen (2014). Comparative proteomic analyses provide new insights into low phosphorus stress responses in maize leaves. PLoS One 9:98215-98230

Zhang ZL (1990). Experimental Instruction in Plant Physiology, pp:154-155. Higher Education Press, Beijing, China

Zhou Y, L Hu, H Wu, L Jiang, S Liu (2017). Genome-wide identification and transcriptional expression analysis of cucumber superoxide dismutase (SOD) family in response to various abiotic stresses. Intl $J$ Genomics 2017; Article 7243973

Zou JJ, XD Li, D Ratnasekera, C Wang, WX Liu, LF Song, WZ Zhang, W Wu (2015). Arabidopsis CALCIUM-DEPENDENT PROTEIN KINASE8 and CATALASE3 function in abscisic acid-mediated signalling and $\mathrm{H}_{2} \mathrm{O}_{2}$ homeostasis in stomatal guard cells under drought stress. Plant Cell 27:1445-1460

Zou Q (2000). Experimental Manual on Plant Physiology, pp:159-170. Chinese Agriculture Press, Beijing, China 